\title{
Sistematizar experiências para pensar a prática na educação social
}

Karine dos Santos ${ }^{1}$, Amanda Motta Castro

\section{Resumo}

Este texto foi escrito a partir da realização de uma oficina com educadores sociais do município de São Leopoldo, no estado do Rio Grande do Sul. Apresentamos problematização a respeito da constituição do sujeito educador social. O texto analisa uma prática de formação continuada de educadores sociais a partir da metodologia de sistematização de experiências sobre quatro temas: concepção de educação social; percepção da realidade; processo de desenvolvimento da autonomia do educando; e relação com a defesa de direitos e participação social. O referencial teórico da educação popular foi o aporte desta reflexão. Constatamos a importância da sistematização no processo de formação, pois, sistematizando nossas práticas, aprendemos e ensinamos com elas e a partir delas.

\section{Palavras-chave}

Educador Social. Formação. Sistematização. Metodologia.

1. Doutoranda em Educação pela Universidade do Vale do Rio dos Sinos, bolsista Capes. E-mail: karinesan@ gmail.com.

2. Doutoranda em Educação pela Universidade do Vale do Rio dos Sinos, bolsista Capes. E-mail: motta.amanda@ terra.com.br. 


\title{
Systematizing experiences to think social education practice
}

\author{
Karine dos Santos*, Amanda Motta Castro**
}

\begin{abstract}
This text originated from a workshop for social educators in the city of São Leopoldo, state of Rio Grande do Sul, Brazil. We present a problematization regarding the constitution of the subject as a social educator. The text analyzes a practice of continuing education for social educators from the methodology of systematization of experiences on four themes: concept of social education; perception of reality; process of development of the learner's autonomy; and relations with the right defense and social participation. The popular education theoretical framework guided this reflection. It was noticed the importance of systematizing the education processes, since we learn and teach both with and from them.
\end{abstract}

\section{Keywords}

Social Educator. Education. Systematization. Methodology.

* PhD student in Education, Vale do Rio dos Sinos University, State of Rio Grando do Sul, Brazil. Capes scholar. E-mail: karinesan@gmail.com.

* PhD student in Education, Vale do Rio dos Sinos University, State of Rio Grando do Sul, Brazil. Capes scholar. E-mail: motta.amanda@terra.com.br. 


\section{Introdução}

A educação popular aponta a experiência como relevante por ser considerada desencadeadora da produção do conhecimento. Pensar a prática, tendo como base a sistematização da experiência, de alguma forma, é dar conta dos processos históricos que, por meio dos discursos, posicionam sujeitos que produzem suas experiências. Não são os indivíduos que têm experiências, mas os sujeitos que são constituídos por elas. A experiência não é compreendida como a origem de nossa explicação ou a evidência autorizada que fundamenta o conhecimento, mas sim como aquilo que buscamos explicar, aquilo sobre o qual se produz conhecimento (SCOTT, 1999).

De acordo com Falkembach (1995; 2008), quando pensamos em sistematizar experiências, queremos pensar a prática e, com isso, produzir conhecimento. A sistematização de experiências, constituída a partir da tradição latino-americana da educação popular, redefiniu, na segunda metade do século XX, paradigmas, modalidades de intervenção pedagógica e de investigação social. Configurou-se como um instrumental metodológico voltado ao acompanhamento de práticas sociais intencionadas à transformação social e que se distinguem a partir dos sujeitos integrantes de movimentos sociais, sindicatos, ONGs, escolas e projetos governamentais. Nos anos de 1970 e 1980, na América Latina, o tema da sistematização surge sustentado por correntes teórico-práticas que se estimulam, retroalimentam-se e convergem entre si o trabalho social reconceitualizado, a educação de adultos, a educação popular, a teologia da libertação e a investigação-ação-participativa (FALKEMBACH, 2008).

Para Falkembach (1995), sistematizar é transformar a própria experiência em objeto de estudo; desconstruir e reconstruir ordenadamente as práticas de educação, organização e promoção social; construir conhecimento coletivamente; constituir-se num processo radical; e promover mudanças na prática e em seus agentes.

Em uma perspectiva metodológica, entendemos que a sistematização contribui com os processos desenvolvidos por educadores sociais por dois motivos: o primeiro estaria centrado na possibilidade de visualização de seu processo como constituição de uma identidade profissional; e o segundo, como possibilidade de sistematização do conhecimento a partir do processo de reflexão-ação-reflexão que a metodologia proporciona, desde as ações desenvolvidas no âmbito de seu campo de atuação e os processos de formação continuada.

Assim, com o objetivo de compreender como o processo de formação continuada contribui para a constituição da identidade do educador social e seus reflexos na prática cotidiana, nos aproximamos de um grupo de educadores vinculados à Secretaria Municipal de Assistência, Cidadania e Inclusão Social (SACIS) ${ }^{3}$ da cidade de São Leopoldo, no Rio Grande do Sul, para, coletivamente, constituirmos um processo de sistematização de experiências de um processo de formação vivenciada pelo grupo.

3. No município de São Leopoldo, região do Vale do Rio dos Sinos, no Estado do Rio Grande do Sul, a Secretaria Municipal de Assistência, Cidadania e Inclusão (SACIS) atua na perspectiva de promoção da cidadania, tendo por base a Política Nacional de Assistência Social (Pnas) e a Norma Operacional Básica do Sistema Único de Assistência Social (NOB/SUAS). O objetivo da SACIS é, por meio da proteção social, garantir segurança de sobrevivência (de rendimentos e autonomia), de acolhida e de convívio ou vivência familiar. A SACIS está estruturada em quatro diretorias: Diretoria Geral, Diretoria de Planejamento e Gestão Estratégica, Diretoria de Proteção Social Básica e Diretoria de Proteção Social Especial. Disponível em: <http://sacis-saoleopoldo.blogspot.com.br/> e <https:// www.saoleopoldo.rs.gov.br.> Acesso em: 15 ago. 2012. 
Estetexto procura contemplar, inicialmente, a contextualização do tema "educador social" frente à tradição da educação popular. Depois, apresentar o grupo de educadores na sua relação com seu campo de atuação. Essa contextualização visou a problematizar o processo de aprendizagem do ofício pelos próprios educadores ao analisar o significado da formação continuada a partir da vivência da metodologia de sistematização de experiências.

\section{Entre a experiência e a formação}

Sabemos que o campo de práticas educativas não escolares utiliza, sobretudo, a experiência como foco de seu trabalho. Orientados para uma prática social de intervenção, seus agentes ocupam

um espaço profissional desenhado no ponto de encontro e de cruzamento entre a área do trabalho social e a área da educação (CARVALHO; BAPTISTA, 2004, p. 83).

Na perspectiva da educação popular, são considerados como agentes de mudança, pois seu trabalho tem impacto na cultura e na história das comunidades nas quais inscrevem a sua ação. Na mesma direção, Gohn (2007) afirma que os educadores sociais, como dinamizadores de possíveis mudanças sociais paradigmáticas, representam um painel rico, amplo e estimulante, posto ser pessoas que, em alguma medida, fazem diferença no cotidiano das comunidades em que atuam. Desse modo, sabemos que esse movimento de mudança social faz parte do que motiva o educador social na sua prática cotidiana (GEBARA, 2005; FREIRE, 1987).

Ideais de transformação social foram difundidos pela educação popular, que tem por objetivo básico a formação de sujeitos críticos, capazes de questionar e movimentar as estruturas sociais. Tais pressupostos foram escritos por Freire em uma de suas principais obras, Pedagogia do Oprimido, e retomados por outros escritos dele. Freire (1987) defende que o ato educativo seja pautado na formação crítica dos educandos, o que ocorre por meio da problematização e da leitura do mundo, com o objetivo de levá-los ao que se denomina processo de conscientização. Uma educação que acontece na relação de homens e mulheres entre si, mediatizados pelo mundo (FREIRE, 1987a).

Segundo Paludo (2001), a educação popular representa uma concepção de educação que inicia sua gestação com o projeto de modernidade brasileira e latino-americana, cujos contornos inovam-se e começam a se delinear, de forma mais clara, nos anos de 1960 e aprofundados nas décadas de 1970 e 1980. A figura do educador social está presente e tem o papel de desenvolver estratégias que envolvam a cultura, além de propor novas formas de inserção e de participação popular em questões que dizem respeito às classes populares por meio de uma ação educativa.

O processo educativo desenvolvido por Paulo Freire surgiu como expressão educacional de um projeto político, ou seja, um projeto comprometido com um ideal de mudança social. Assim, práticas pautadas nos ideais freireanos desenvolvem sua ação no campo social com forte conotação no educativo, um educativoemancipatório estimulador de mudanças. Nesse sentido, a extensão do trabalho no campo social, marcado por intervenções a todos os segmentos populacionais em esferas públicas e privadas, confirma a expressão do trabalho do educador social. Ele é um dos atoreschave na proposição de práticas educativas emancipatórias nos espaços de educação.

Proveniente das mais diversas experiências e formações, Gohn (2010) sugere que os educadores assumam o papel de "tradutores sociais e culturais". Esta tradução estaria vinculada à busca de 
mecanismos de diálogo entre setores sociais usualmente isolados, invisíveis, incomunicáveis, ou simplesmente excluídos de uma vida cidadã. (GOHN, 2010, p. 52).

Romans, Trilla e Petrus (2003) apresentam um dos principais desafios do exercício profissional do educador social que se baseia na orientação e no enriquecimento dos processos educativos. Isso requer que o sujeito vá além do conhecimento técnico e seja capaz de estabelecer uma relação de empatia, escuta e resposta com seu educando, acrescentando uma perspicaz análise das especificidades e ambiguidades do contexto no qual se insere.

Na perspectiva freireana, o educador não é apenas aquele que educa, mas que também é educado, ou seja, ele é parte do processo. Para Freire (1987), conhecer e transformar não constituem dualidades da ação educativa, mas aspectos distintos de uma mesma unidade, mediante a práxis histórica do ser humano que, por sua vez, indica um tempo de possibilidade, e não de determinismos (FORSTER, 2010).

É necessário retomar a perspectiva educativa-emancipatória proposta por Freire e disseminada por homens e mulheres que, nos últimos 40 anos, têm se debruçado em aprofundar a educação popular às práticas desenvolvidas pelos educadores sociais, e direcionar o olhar que buscamos empenhar na tentativa de sistematização de experiências com o referido grupo.

\section{Pensar a prática, sistematizando experiências}

O grupo de educadores participantes deste processo está vinculado à Secretaria Municipal de Assistência Cidadania e Inclusão Social (SACIS), que busca trabalhar dentro das diretrizes da atual Política Nacional de Assistência Social (SUAS) numa perspectiva emancipatória não assistencialista. A
SACIS desempenha a sua ação a partir da compreensão de que todas as ações sociais são permeadas por um processo formativo, tendo por inspiração os princípios da educação popular. Os educadores estão vinculados à Proteção Social Básica, desenvolvendo seu trabalho nos espaços dos Centros de Referência em Assistência Social (CRAS) frente a dois projetos distintos: o Programa Auxílio Solidário (PAS) e o Projovem Adolescente (PJA).

O PAS é um programa municipal de transferência de renda que, desde 2005, é desenvolvido com pessoas com idades entre 25 e 60 anos. O programa surgiu como uma política de governo para enfrentar o agravamento da situação de pobreza no município, atendendo à população em situação de vulnerabilidade social por estarem essas pessoas inseridas num contexto de precarização das condições de vida e de trabalho. Além da transferência de renda, o programa objetiva desencadear um processo educativo que possa contribuir para a construção de condições que oportunizem a autonomia gradativa da população atendida. Divididos em 28 grupos, o PAS envolve cerca de 200 adultos em suas atividades. O Projovem Adolescente (PJA) foi implantado em São Leopoldo no ano de 2008 e é um serviço socioeducativo integrante da Política Nacional de Assistência Social (PNAS), uma política de proteção social com caráter universalizante e materializada pelo Sistema Único de Assistência Social (SUAS). O PJA, em suas propostas de ação, articula as duas proteções sociais - básica e especial -, além de buscar desenvolver a segurança de acolhida e o convívio familiar e comunitário. Sendo assim, é um serviço socioeducativo de convivência e fortalecimento de vínculos, voltado aos adolescentes de 15 a 17 anos. O foco de trabalho do PJA é o fortalecimento da convivência familiar e o retorno ou a permanência do adolescente na escola. O público atendido 
pelo projeto abrange famílias beneficiárias do Programa Bolsa Família. Dividido em 21 coletivos, atendeu 386 jovens em 2011. A necessidade expressa pela SACIS de instituir processos de formação de educadores definiu o foco da nossa intervenção, que se restringiu à sistematização da experiência vivenciada no ano de 2011 e em meados de 2012. A dinâmica proposta dividiu-se em duas oficinas de trabalho com duração de três horas cada. Iniciamos as atividades provocando narrativas sobre o tema "De repente, educador social" com o objetivo de perceber, no grupo, como profissionais de áreas distintas ${ }^{4}$ vão construindo a sua práxis no contexto do trabalho no campo social.

Numsegundomomento, propomosanalisar coletivamente quatro temas que permearam o processo de formação dos educadores e que se constituem em conhecimento fundamental para a compreensão de sua prática. Assim, ficou definido que a sistematização estaria centrada nos seguintes aspectos: concepção de educação social; percepção da realidade; processo de desenvolvimento da autonomia do educando; e relação com a defesa de direitos e participação social. Os dispositivos metodológicos utilizados procuraram contemplar momentos individuais e coletivos de reflexão. Divididos nas quatro temáticas, o momento inicial sugeria que cada um entrevistasse cada colega acerca de seu tema, anotando a reação verbal frente ao questionamento. Em seguida, reunidos em seus grupos temáticos, a proposta era realizar uma análise preliminar dasfalas coletadas, tendo como aporte teórico verbetes extraídos do Dicionário Paulo Freire (STRECK; REDIN; ZITKOSKI; 2010), para, finalmente, partilhar as percepções que conseguiram construir durante o processo, num esforço de síntese do que foi mais significativo.

\section{$\mathrm{Na}$ ação de perceber-se educador social}

O processo de sistematização iniciouse pela expressão das trajetórias individuais e pelos motivadores que condicionaram a vinculação com esse campo de trabalho. Como resultado desse momento, conseguimos ter uma visão da heterogeneidade desse grupo de educadores, o que, de certa forma, contribui para o entendimento de suas afirmações. Um destaque inicial é a formação dos educadores, dos quais $25 \%$ possui ensino superior completo e $50 \%$ está em processo de formação. Do percentual que tem apenas o ensino médio, todos possuem o curso técnico normal. As áreas de ou em formação vão desde Administração, Design, Fisioterapia, Engenharia Civil, Arquitetura, Relações Públicas a Serviço Social, Teologia, Educação Física, Letras e Pedagogia. $\mathrm{O}$ interesse em investir na seleção para o cargo de Educador Social teve como mote principal a curiosidade e a remuneração. Segundo os próprios educadores, muitos não sabiam, no ato da inscrição, do que se tratava a tarefa que estavam prestes a desempenhar, como podemos ver nas falas a seguir:

Assim como muita gente, eu não fazia ideia do que seria. Tanto que eu achei que era para trabalhar como professor mesmo, com alguma coisa como reforço escolar, alguma coisa assim. (Educadora Maria).

Fiz o processo seletivo sem saber o que eu ia fazer, não sabia o que era CRAS. Tudo totalmente novo para mim. Então eu demorei algumas semanas para ir descobrindo $\mathrm{O}$ serviço. (Educador João).

Caí de paraquedas, nunca trabalhei nessa área, não conhecia o CRAS, nunca tinha ouvido falar. (Educador Pedro).

Não tinha ideia de como era um trabalho social. (Educador Paulo).

4. Vale destacar que se trata de educadores que, por meio de um edital público, foram selecionados para atuação nessa Secretaria, tendo como critério básico para a sua investidura apenas o ensino médio completo. Assim, configurou-se um grupo de áreas muito diversas e com pouca experiência no campo social. 
Podemos verificar que o grupo não sabia exatamente o que era o trabalho no campo social, quais seus pressupostos, metodologias e objetivos. Isso, de um lado, mostra a fragilidade da área, o que é uma realidade frequente nesse campo em que diferentes profissionais veem possibilidades de inserção ou permanência no mercado de trabalho, ainda que não tenham vinculação com a sua formação inicial, nem sabendo ao menos o que os espera. Segundo Zuchetti e Moura (2010, p. 16), esses profissionais, quando inseridos no campo social,

se veem frente aos desafios de uma área complexa e contraditória, que exige conhecimentos pertinentes e a apropriação de conceitos que extrapolam ou evidenciam as falhas da sua formação acadêmica.

$\mathrm{Na}$ tarefa de aprender a ser educador social, a preocupação com a descoberta do que fazer e como fazer parece constante. As dúvidas mobilizam diferentes compreensões, como a ideia de aprender fazendo e a possibilidade de fazer com o outro:

E fui aprendendo assim, no dia a dia, que eu acho que é isso mesmo, tu está lá tem que se virar. Isso é o que faz com que a gente aprenda a ser educador. (Educadora Roberta).

Tá, eu sou uma educadora social! Vou chegar lá pra falar pra o grupo e tal. E, depois de um tempo, tu começa a perceber que tu não vai lá falar pra o grupo, tu vai lá ouvir o teu grupo. Exatamente, tu vai lá ouvir eles, falar ao mesmo tempo, parece que tu tá ensinando e aprendendo. (Educadora Sara).

Na iminência de ocupar o lugar de educador - articulando com grupos, desenvolvendo atividades e discutindo temas diversos -, os relatos demonstram que a prática é o lócus privilegiado de formação do educador social e que acontece na práxis de um cotidiano marcado pelo desafio e a permanente aprendizagem. Além disso, indicam que um dos maiores desafios enfrentados é o descortinar de realidades desconhecidas até então:

\begin{abstract}
No começo assim assusta um pouco, é muita novidade. A realidade é nua e crua, não que a gente viva em um mundo à parte, mas o mundo dos nossos educandos é muito diferente do nosso né? As perspectivas de vida, o modo de ver as coisas então, isso assusta no início, mas a gente acaba se identificando e vendo possibilidades. (Educador João).
\end{abstract}

Aquele monte de informação sobre um mundo completamente desconhecido. (Educadora Maria).

Este tema pode ser mais bem aprofundado nas discussões acerca do tema "percepção da realidade". A síntese apresentada pelo grupo responsável em analisar esse item considerou que, em sua maioria, a realidade é "injusta, cruel, desigual, preconceituosa e diferente entre as classes" e que o educador social ocupa um lugar de reconhecedor dessa realidade, referindo ser "importante conhecer a realidade dos educandos para poder 'propor' as nossas atividades, buscando melhorias 'dessa' realidade". Essa melhoria estaria atrelada à ideia de mudança social, mas uma mudança do outro, ou seja, o sujeito-educando é quem ocupa o lugar de buscar uma mudança, estimulado pelo trabalho do educador social. Segundo as falas dos próprios educadores, o papel do educador social frente à realidade seria de:

Observador da realidade. O educador tem uma realidade e o educando tem outra. (Educador João).

Primeiro observar este educando na sua realidade. Conhecer o contexto onde ele está inserido, conhecer as concepções dos educandos, forma como eles se veem na sua realidade. (Educadora Maria).

Conhecer o território, conhecer as pessoas para estabelecer vínculos. (Educador Pedro).

Conhecer o meio onde o educando vive, os 
espaços que ele frequenta o que faz conhecer a sua vida e tentar se aproximar da realidade dele. (Educadora Sara).

Reconhecer a realidade do educando é fundamental para a construção de uma intervenção situada e coerente. Freire (1976, p. 32) reflete sobre a leitura de mundo e a leitura da realidade dizendo que esta "não é só dado objetivo, o fato concreto, senão também a percepção que o homem tem dela". Desse modo, compreender a realidade é compreender os fatos como partes e entender que eles abarcam uma totalidade maior. Para Gadotti (2008, p. 350),

ler o mundo, a partir desta perspectiva, significa, então, compreender que os fenômenos sociais estão vinculados a uma realidade macrossocial que imprimi neles a sua marca histórica e seus significados culturais.

Logo, podemos perceber que ler o mundo é uma tarefa complexa. Esse foi um tema bastante lapidado por Freire, que acreditava que os homens e as mulheres eram capazes de apreender a realidade e agir sobre ela. Em Pedagogia da Autonomia, ensinou:

O homem não pode participar ativamente na história, na sociedade, na transformação da realidade se não for ajudado a tomar consciência da realidade e da sua própria capacidade para transformar. Ninguém luta contra forças que não entende cuja importância não meça, cujas formas e contornos não discirna. (FREIRE, 1996, p. 48).

Em consonância com o legado de Freire, um dos educadores afirma:

Ela é transformadora. Sou otimista em relação à realidade que vivemos. Não dá para mudar tudo, mas muita coisa dá para fazer. (Educadora Sara).
No entanto, o papel do educador social, segundo as referências da maioria dos educadores frente à mudança da realidade, está vinculado a uma ideia de quem vê o processo de fora e procura intervir de alguma forma. Contudo, a intervenção não se dá no sentido de uma implicação com essa mudança, porque esse movimento é do outro, que vive uma realidade diferente. O educador social não se vê num processo coletivo de mudança; sua visão está vinculada à ideia de estimulador de mudanças que são externas a eles.

[...] tentar uma mudança, mas a gente sabe que é muito difícil, muito complicado. É triste a realidade e sempre há um limitador. (Educadora Roberta).

[...] mesmo que eles (educandos) se proponham a mudar o que está acontecendo sempre vai ter um empecilho no caminho. (Educador Paulo).

As percepções de que a mudança da realidade é difícil, triste, desafiadora estão muito vinculadas a um sentimento desperto na observação de determinada realidade, demonstrando a necessidade de aprofundamento sobre essa questão no sentido de entendimento dessa relação. De alguma forma, vemos a frágil relação dos educadores socais com esse processo, dado que, de acordo com Weyh (2008), para ocorrerem mudança e transformação social, é imprescindível engajamento e comprometimento em favor dos oprimidos e, sem esse caráter, não temos mudança e transformação, devendo esse movimento partir também do educador. Segundo Machado (2008), autonomia é uma categoria central na obra de Freire. No que se refere à percepção do processo de desenvolvimento da autonomia do educando, os educadores, de um modo geral, confirmam a importância do reconhecimento da realidade e do estabelecimento de vínculos afetivos para 
a construção de uma relação de confiança. Somente assim poderiam iniciar um processo de estímulo à construção da autonomia do educando.

No primeiro momento o educador tem que trabalhar junto com o educando, a sua realidade, para conhecê-la e poder interagir junto a este. É necessário conhecer a realidade em que vive para poder entender suas necessidades. (Educador Pedro).

Faz-se necessário primeiramente conhecer a realidade e a cultura do educando e estabelecer vínculos afetivos e relações de confiança entre educador e educando. (Educador Paulo).

Autonomia, de acordo com Freire (apud MACHADO, 2008, p. 56), é "Liberar o ser humano das cadeias do determinismo neoliberal, reconhecendo que a história é um tempo de possibilidades". Segundo a opinião geral do grupo, a autonomia é construída num "processo gradativo, permanente e transformador", sustentando a afirmação de Freire (1987) de que a "autonomia vai se construindo na experiência". Esse foi o tema de maior debate e divergência entre o grupo que se destacou pelo interesse em compreender como se interpreta esse processo. Num esforço de análise, indicam:

Nós, educadores, podemos analisar esse momento de inúmeras formas. Na medida em que ele vai adquirindo mais autonomia, ele também vai questionando mais. Daí a gente ficou na dúvida se ele consegue analisar, compreender e questionar ou se ele só questiona sem analisar e compreender. Ele tem que compreender para questionar? Ou ele só questiona e não analisa? Ou ele compreende, analisa, mas não questiona. Eu acho que um primeiro passo é ele te compreender, compreender a sua realidade para começar a questionar ela. (Educadora Rita).

O processo de construção da autonomia exige reflexão crítica e prática (FREIRE, 1987). Assim, são pertinentes os questionamentos explicitados pelos educadores sobre esse tema, demonstrando profunda preocupação com a construção de percepções por parte dos educandos. No entanto, divergem do enunciado por Freire no que diz respeito à construção da autonomia, por indicarem que esse processo é despertado pelo próprio educando, num movimento próprio.

Lento, às vezes não acontece. Nós temos a obrigação de apontar os caminhos. O educador exerce papel fundamental para que o processo ocorra. Às vezes não acontece por causa do educando, pois deve partir mais do educando. (Educador João).

Alguns querem a mudança, outros não. Mas não parte só de nós fazê-los perceber. (Educadora Roberta).

Bem lento, difícil de encontrar meios para promoção. (Educador Pedro).

Freire (1996, p. 71 ) defende que "o trabalho de construção de autonomia é o trabalho do educador com os educandos e não do educador consigo mesmo". Contudo, as afirmações e os questionamentos postos demonstram o despertar de um grupo de educadores que, em suas primeiras experiências com o campo social, já apresentam comprometimento e desejo de construção de suas percepções frente a esse campo. Como expressão desse compromisso, percebemos o empenho que tiveram em listar algumas pistas para compreender o início do processo de construção da autonomia dos educandos, que tem implicação direta com a ação desempenhada pelo próprio educador:

No momento em que consegue compreender, analisar a sua realidade. Quando parte dele a busca pela sua melhora, quando consegue perceber que depende dele e não de alguém ou instituição. (Educadora Mariana). 
Quando o educando consegue buscar objetivos como nós, e principalmente, quando ele consegue pensar sozinho, se questionar. Quando vemos os educando participando, querendo compreender já iniciamos o processo. (Educadora Julia).

Quando eu vejo que eles estão buscando respostas para perguntas que eles não sabem. Buscando respostas que mudem a sua vida ou realidade. (Educador Ricardo).

Já no último item de análise - relação com a defesa de direitos e participação social -, a premissa de que os educadores sociais percebem os processos olhando de fora para dentro se confirma. Suas falas apontam que essa relação é estimulada por eles próprios para conquistar espaços "para" os educandos.

A partir das respostas nós identificamos duas posturas. Uma é a visão de que nós, educadores, lutamos pela democracia e apontamos caminhos para os outros. E a segunda é uma visão de que essa relação é limitada e muitas vezes não acontece. (Educadora Maria).

Suas opiniões ficam muito distantes do preconizado por diferentes autores que se dedicam a esse tema (STRECK, 2005; WEYH, 2009; DEMO, 1986) e que defendem que essa relação está inserida numa dinâmica coletiva, de construção de uma perspectiva de sociedade democrática e inclusiva. Entretanto, essa ideia não está presente na reflexão de alguns educadores, que afirmam:

Nós, educadores, constantemente, lutamos pela democracia, tentando dar voz a pseudocidadãos nas lutas por seus direitos. Assumimos o papel fundamental de apontar caminhos aos oprimidos para que estes, partindo de si, possam buscar seu direito a cidadania. (Educador Paulo).

Não existe. Todos defendem, mas não existe na maioria dos casos. (Educador Pedro).
Limitada, não pela minha ação, mas no final ela não acontece, mas ao mesmo tempo ela é motivadora, instigante, porém, às vezes, decepcionante. (Educadora Roberta).

Na contramão, outro grupo confirma que esse processo está inserido numa prática coletiva quando indicam:

O educador social trabalha com a inclusão e a emancipação do indivíduo ou de um grupo social, resgatando direitos que lhe foram negados. O papel do educador social é trabalhar junto a eles para garantir o resgate desses direitos junto à sociedade. (Educadora Julia).

A defesa de direitos entendo como gestões básicas de vida, ir e vir, e a relação participação social é como tu busca por esses direitos de como levar (melhorar) se apropria e a tua participação social em que tu esta na comunidade ou como um todo. (Educador Ricardo).

Essa relação é o objetivo do educador, que tenham autonomia com conhecimento de seus direitos, mudar a realidade. (Educadora Mariana).

O movimento que implica a garantia e a defesa dos direitos é horizonte do trabalho do educador social, uma vez que ele se considera um estimulador de mudança. Considerando o perverso cenário histórico de déficit de direitos, torna-se fundamental a ação do educador para a desnaturalização e a denúncia da reprodução ampliada das desigualdades sociais, assim como o reconhecimento e a universalização dos direitos em sintonia com uma prática cidadã. No bojo desse contexto, os ideais de mudança social são fulcrais para a conquista da cidadania universal. Tal proposição mostra-se essencial para a construção de novos patamares de sociabilidade. Uma sociabilidade que tenha como horizonte a emancipação humana, operando mediante a recusa à opressão e à exploração - de classe, gênero e etnia (GEBARA, 2000; SAFFIOTI, 2004). 


\section{Considerações finais}

O exercício do diálogo promovido pela metodologia proposta favoreceu a elaboração de relações entre o contexto da prática e o contexto da formação. O enfrentamento de opiniões divergentes e a proposição de consensos sinalizam formas de comprometimento com os processos educativos desenvolvidos por cada um. Na ação de perceber-se educador social, fica evidente a importância da sistematização como processo reflexivo da ação e elaboração de perspectivas comum a todos.

Para Romão (2008), a educação freireana constitui-se na práxis, que ocorre na indispensável relação entre prática e teoria. É importante destacar que a ordem freireana é prática e teoria, haja vista que esta deve ser construída e refletida a partir daquela. Freire (1987b) diz que a educação do educador é processual, lenta e construída na cotidianidade, no cotidiano tecido na lida da práxis do educador.

Na medida em que as discussões vão apresentando elementos que reforçam a troca de experiências, os estudos sistemáticos e a interlocução com palestrantes, convidados e demais técnicos da rede, apresentam a evidência do significado que a formação continuada ganha no processo de constituição do ser educador social. Além disso, os próprios educadores são unânimes em dizer que a formação é fundamental para aprofundar estudos e responder às questões do cotidiano, mas alertam que se deve ir além, demonstrando compromisso com este campo de ação.

$\mathrm{O}$ esforço de compreensão frente aos temas propostos nessa sistematização constituiu-se num momento reflexivo possível de externalização de pontos de vista, de formas de compreensão de mundo e das relações estabelecidas com os contextos da prática e seus educandos. Nessa direção, os processos formativos aliados à metodologia de sistematização de experiências podem configurar-se como instrumentos fundamentais de reflexão e construção de visões de mundo, de sociedade e de ser humano, numa dinâmica que oportunize reconhecer o papel do educador social e permita a elaboração de projetos de ação que promovam, de fato, uma educação verdadeiramente emancipatória.

Contudo, há de se considerar que esse grupo de educadores está dando início a um processo de reconhecimento de seu lugar como educador, pois a sua característica principal está marcada por um processo tanto experiencial quanto formativo. De um modo geral, as percepções demonstram o interesse em compreender os processos aliado a um desejo que se mostra permanente em aprender mais.

Nesse sentido, a metodologia de sistematização de experiências contribuiu para o apontamento do que foi significativo no processo formativo e das lacunas que poderão receber maior empenho na sua continuidade. Esta é, sem dúvida, uma das belezas da formação em Educação Popular: o movimento contínuo de buscar aprender, ensinar, lutar e transformar. Entendemos que a sistematização contribui para esse processo, pois, sistematizando nossas práticas, aprendemos e ensinamos com elas e a partir delas.

\section{Referências}

BRANDÃO, C. R. Em campo aberto: escritos sobre educação popular. São Paulo: Cortez, 1995.

CARVALHO, A.; BAPTISTA, I. Educação social: fundamentos e estratégias. Porto: Porto Editora, 2004. (Coleção Educação e Trabalho Social). 
FALKEMBACH, E. M. F. Sistematização: juntando cacos, construindo vitrais. ljuí: Unijuí, 1995. (Cadernos UNIJUÍ - Série Educação 23).

. Sistematização em educação popular: uma história, um debate. In: REUNIÃO ANUAL DA ANPED, 30., 2008. Caxambu-MG. Anais... Disponível em: <http://www.anped.org.br/ reunioes/30ra/trabalhos/GT06-3316--Int.pdf>. Acesso em: 3 out. 2013.

FREIRE, P. Ação cultural para a liberdade e outros escritos. Rio de Janeiro: Paz e Terra, 1976.

1996.

Pedagogia da autonomia: saberes necessário à prática educativa. São Paulo, Paz e Terra,

. Pedagogia do oprimido. Rio de Janeiro: Paz e Terra, 1987a.

FREIRE, P.; SHOR, I. Medo e ousadia: o cotidiano do professor. Rio de Janeiro: Paz e Terra, 1987b.

FORSTER, M. M. Educador/Educando. In: STRECK, D.; REDIN, E.; ZITKOSKI, J. J. (Org.). Dicionário Paulo Freire. Belo Horizonte: Autêntica, 2008.

GADOTTI, M. Realidade. In: STRECK, D.; REDIN, E.; ZITKOSKI, J. J. (Org.). Dicionário Paulo Freire. Belo Horizonte: Autêntica, 2008.

GEBARA, I. Rompendo o silêncio: uma fenomenologia feminista do mal. São Paulo: Vozes, 2000.

As águas do meu poço. São Paulo: Brasiliense, 2005.

GOHN, M. G. Educação não formal e o educador social: atuação no desenvolvimento de projetos sociais. São Paulo: Cortez, 2010.

. Educação popular na América Latina no novo milênio: impactos do novo paradigma. In: REUNIÃO ANUAL DA ENPED, 24., 2001. Caxambu. Anais... Disponível em: < http://www.anped. org.br>. Acesso em: 20 ago. 2012.

JARA HOLLIDAY, J. O. La sistematización de experiências y las corrientes innovadoras del pensamiento latinoamericano: una aproximación histórica. La Pirágua, Panamá, n. 23, p. 7-16, 2006.

MACHADO, R. C. F.. Autonomia. In: STRECK, D.; REDIN, E.; ZITKOSKI, J. J. (Org.). Dicionário Paulo Freire. Belo Horizonte: Autêntica, 2008.

NETTO, J. P. A.; BEHRING, E. A emancipação política e a defesa de direitos. Revista Serviço Social e Sociedade, São Paulo: Cortez, 2007.

PALUDO, C. Educação popular em busca de alternativas: uma leitura desde o campo democrático e popular. Porto Alegre: Tomo Editorial, 2001.

ROMANS, M.; TRILLA, J.; PETRUS, A. Profissão educador social. Porto Alegre: Artes Médicas, 2003.

ROMÃO, J. Educação. In: STRECK, D. R.; REDIN, E.; ZITKOSKI, J. J. (Org.). Dicionário Paulo Freire. Belo Horizonte: Autêntica, 2008. 
SAFFIOTI, H. Gênero e patriarcado. In: VENTURI, G.; RECAMÁN, M.; OLIVEIRA, S. de. A mulher brasileira nos espaços públicos e privados. São Paulo: Fundação Perseu Abramo, 2004.

STRECK, D.; REDIN, E.; ZITKOSKI, J. J. (Org.). Dicionário Paulo Freire. Belo Horizonte: Autêntica, 2010.

SCOTT, J. Experiência. In: SILVA, A. (Org.). Falas de gênero: teorias, análises, leituras. Florianópolis: Editora das Mulheres, 1999.

ZUCHETTI, D.; MOURA, E. Práticas socioeducativas e formação de educadores: novos desafios no campo social. Revista Ensaio, Rio de Janeiro, v. 18, n. 66, p. 9-28, jan./mar., 2010.

WEYH, C. Mudança/Transformação Social. In: STRECK, D. R.; REDIN, E.; ZITKOSKI, J. J. (Org.)

Dicionário Paulo Freire. Belo Horizonte: Autêntica, 2008.

Submetido em 10 de abril de 2014.

Aprovado em 15 de maio de 2014. 